October 1999 • NREL/CP-520-26933

\title{
Techniques for Measuring the Composition of Hydrogenated Amorphous Silicon-Germanium Alloys
}

\section{Preprint Prepared for ICAMS}

B.P. Nelson, Y. Xu, J.D. Webb, A. Mason, R.C. Reedy, and L.M. Gedvilas National Renewable Energy Laboratory

W.A. Lanford

Department of Physics, SUNY Albany

Presented at the International Conference of Amorphous and Microcrystalline Semiconductors (ICAMS)

Snowbird, Utah

May 22-29, 1999

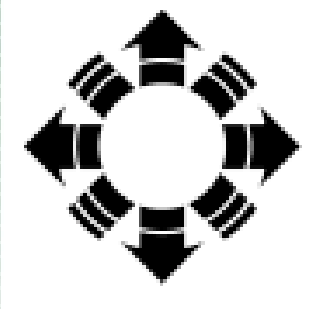

\section{NPEI}

National Renewable Energy Laboratory

1617 Cole Boulevard

Golden, Colorado 80401-3393

NREL is a U.S. Department of Energy Laboratory

Operated by Midwest Research Institute $\bullet$ Battelle $\bullet$ Bechtel

Contract No. DE-AC36-98-G010337 


\section{NOTICE}

The submitted manuscript has been offered by an employee of the Midwest Research Institute (MRI), a contractor of the US Government under Contract No. DE-AC36-99G010337. Accordingly, the US Government and MRI retain a nonexclusive royalty-free license to publish or reproduce the published form of this contribution, or allow others to do so, for US Government purposes.

This report was prepared as an account of work sponsored by an agency of the United States government. Neither the United States government nor any agency thereof, nor any of their employees, makes any warranty, express or implied, or assumes any legal liability or responsibility for the accuracy, completeness, or usefulness of any information, apparatus, product, or process disclosed, or represents that its use would not infringe privately owned rights. Reference herein to any specific commercial product, process, or service by trade name, trademark, manufacturer, or otherwise does not necessarily constitute or imply its endorsement, recommendation, or favoring by the United States government or any agency thereof. The views and opinions of authors expressed herein do not necessarily state or reflect those of the United States government or any agency thereof.

Available electronically at http://www.doe.gov/bridge

Available for a processing fee to U.S. Department of Energy and its contractors, in paper, from:

U.S. Department of Energy

Office of Scientific and Technical Information

P.O. Box 62

Oak Ridge, TN 37831-0062

phone: 865.576 .8401

fax: 865.576.5728

email: reports@adonis.osti.gov

Available for sale to the public, in paper, from:

U.S. Department of Commerce

National Technical Information Service

5285 Port Royal Road

Springfield, VA 22161

phone: 800.553 .6847

fax: 703.605.6900

email: orders@ntis.fedworld.gov

online ordering: http://www.ntis.gov/ordering.htm

Printed on paper containing at least $50 \%$ wastepaper, including $20 \%$ postconsumer waste 


\title{
Techniques for Measuring the Composition of Hydrogenated Amorphous Silicon-Germanium Alloys
}

Brent P. Nelson ${ }^{1}$, Yueqin $\mathrm{Xu}^{1}$, John D. Webb ${ }^{1}$, Alice Mason ${ }^{1}$, Robert C. Reedy ${ }^{1}$, Lynn M. Gedvilas $^{1}$, and William A. Lanford ${ }^{2}$

1. National Renewable Energy Laboratory, Golden CO, 80401, USA

2. Department of Physics, SUNY Albany, Albany NY, 12222, USA

\begin{abstract}
We grow hydrogenated amorphous silicon-germanium alloys by the hot-wire chemical vapor deposition technique at deposition rates between 0.5 and 1.4 nanometers per second. We prepared a set of these alloys to determine the concentrations of the alloying elements as measured by various techniques. This set consists of samples throughout the range of germanium alloying from $0 \%(\mathrm{a}-\mathrm{Si}: \mathrm{H})$ to $100 \%(\mathrm{a}-\mathrm{Ge}: \mathrm{H})$. We find that by making the appropriate calibrations and corrections, our compositional measurements agreement between the various techniques. Nuclear reaction analysis, Fourier transform infrared spectroscopy, and secondary ion mass spectrometry (SIMS) all yield similar hydrogen contents, within $\pm 20 \%$ for each sample. Electron probe micro-analysis (EPMA) and SIMS yield silicon and germanium contents within $\pm 7 \%$ of each other with results being confirmed by Rutherford backscattering. EPMA oxygen measurements are affected by highly oxidized surface layers, thus these data show larger $\mathrm{O}$ concentrations than those measured by SIMS.
\end{abstract}

\section{Introduction}

Hydrogenated amorphous silicon-germanium alloys (a-SiGe:H) are integral components of amorphous silicon-based solar cells [1] as the absorber layer in the middle and back cells in stacked or tandem structures [2-4]. Alloying hydrogenated amorphous silicon (a-Si:H) with germanium narrows the optical bandgap of the material, allowing it to adsorb photons from less energetic portions of the solar spectrum. However, these alloys tend to be electronically [5] and structurally [6] inferior to a-Si:H. Therefore, the improvement of a-SiGe:H alloys continues to be an important aspect of a-Si:H-based solar cell research and development.

We grow a-Si:H [7] materials and a-SiGe:H alloys [8] by the hot-wire chemical vapor deposition (HWCVD) process with electronic and structural properties similar to those grown by plasmaenhanced chemical vapor deposition (PECVD). An advantage of the HWCVD process is the ability to grow device-quality materials at greater deposition rates - that have smaller $\mathrm{H}$ content and increased stability compared to PECVD-grown a-Si:H [9]. Both processes produce a-SiGe:H alloys that have an increase in structural heterogeneity at the nanometer scale (e.g., voids or atomic clustering) with increasing Ge content. This increase occurs at $\sim 12$ at. $\%$ Ge for HWCVD-grown a-SiGe:H $[8,10]$ and 20 at.\% for PECVD-grown a-SiGe:H [6]. To our knowledge, little work has been done in the area of compositional measurements of a-SiGe:H grown by HWCVD. In this paper, we compare the results of compositional measurements by various techniques.

Key Words (JNCS index terms): A180, amorphous silicon-germanium (a-SiGe:H), Hot-Wire C185 (HWCVD), I160, S130, Electron Probe Micro Analysis (EPMA), Nuclear Reaction Analysis (NRA), R190, S180, G150 


\section{Experimental Procedures}

For the HWCVD-grown samples reported on in this paper, we used gas-phase ratios of germane to silane plus germane of $0,3,8,17,35,50,70$, and 100 volume $\%$. All other deposition parameters were kept as constant as possible. We fixed the total hydride (silane + germane) flow to $50 \mathrm{sccm}$. We used substrate temperatures between $350^{\circ}$ and $375^{\circ} \mathrm{C}$ (except for the $100 \%$ germane sample that was grown at $285^{\circ} \mathrm{C}$ to avoid microcrystalline formation [8]). We used a chamber pressure of 12 mtorr, a filament temperature of $2000^{\circ} \mathrm{C}$, and a filament-to-substrate spacing of $4.5 \mathrm{~cm} \mathrm{[7].} \mathrm{The} \mathrm{chamber} \mathrm{consists} \mathrm{of} \mathrm{a} \mathrm{single,} \mathrm{standard} \mathrm{vacuum,} \mathrm{six-way} \mathrm{cross}$ (without a load-lock) where the gas flow is perpendicular to the filament [11] in which we obtain a predeposition pressure of less than $5 \times 10^{-6}$ torr.

For this investigation, we codeposited on three different substrates, each for a different type of measurement. We use Corning 7059 glass for measuring electronic properties (e.g., photo- and dark conductivity) and optical gap. We use single-polished crystalline silicon (c-Si), with a resistivity $<0.1 \Omega$-cm, for secondary ion mass spectrometry (SIMS) measurements. We use double-polished c-Si, with a resistivity $>50 \Omega$-cm, for nuclear reaction analysis (NRA) and Fourier transform infrared (FTIR) spectroscopy. We used both types of c-Si substrates for electron probe micro-analysis (EPMA).

We performed the EPMA [12] on these samples with a 5-keV electron beam that probes to an estimated depth of 0.25 to $0.5 \mu \mathrm{m}$. In analyzing the $\mathrm{x}$-ray spectra resulting from the absorption of the electron beam we find only contributions from $\mathrm{Si}, \mathrm{Ge}$, and $\mathrm{O}$ (i.e., these three elements account for the entire mass total). The atomic ratios are then calculated for these three elements. This test is limited to elements having a mass between $\mathrm{Be}$ and $\mathrm{U}$ and thus cannot be used to determine the hydrogen content of samples.

We performed SIMS $[13,14]$ measurements on these samples with a $14.5 \mathrm{keV} \mathrm{Cs}^{+}$beam as the primary ion source. The $\mathrm{Cs}^{+}$beam was operated at 100 nanoamps, at an incident angle of $25^{\circ}$ from surface normal. The beam was raster-scanned to a $150 \mu \mathrm{m}$ square area to remove negative secondary ions from the sample; thus producing a crater in the sample. These secondary ions were accelerated normal from the sample to an electron multiplier detector for counting at 4.5 $\mathrm{keV}$. To minimize crater edge effects, we collected secondary ions only from a $60 \mu \mathrm{m}$ diameter area in the center of the crater. The working pressure in the chamber was $2 \times 10^{-10}$ torr.

We performed FTIR spectroscopy on these samples by measuring the transmission from 450 to $2900 \mathrm{~cm}^{-1}$ at $4 \mathrm{~cm}^{-1}$ resolution. From the IR spectra we calculated the absorption coefficient of the $\mathrm{Si}-\mathrm{H}$ wagging band $\left(640 \mathrm{~cm}^{-1}\right)$ mode [15] and the $\mathrm{Ge}-\mathrm{H}$ bending $\left(570 \mathrm{~cm}^{-1}\right)$ mode. However, the $\mathrm{Ge}-\mathrm{H}$ bands were much less intense than the Si-H bands, exept in the a-Ge:H film. To calculate the $\mathrm{H}$ contents of these films we use the $\mathrm{Si}-\mathrm{H}$ wagging band area [16] and a proportionality constant of $2.6 \times 10^{19} \mathrm{~cm}^{-2}$ developed from FTIR and NRA a-Si:H/Si standards. Note that this constant is slightly larger than used in reference [16]. We found it unnecessary to deconvolute the overlapping bands of the $\mathrm{Si}-\mathrm{H}$ wag and $\mathrm{Ge}-\mathrm{H}$ bend modes for $\mathrm{H}$ content determination, but integrated them together.

manuscript \# TuP7.15, mailed to ICAMS 18, University of Utah, on 9/9/99 
The NRA $[17,18]$ performed on these samples was done at SUNY Albany using a nitrogen-15 ion $\left({ }^{15} \mathrm{~N}\right)$ beam from an accelerator to react with protons in the sample. This resonant reaction results in the emission of a $4.43 \mathrm{MeV} \gamma$-ray, the yield of which is proportional to the concentration of hydrogen in the sample. Because the ${ }^{15} \mathrm{~N}$-proton reaction is at resonance at the penetration depth, various beam energies probe the sample at correspondingly different depths. Thus, varying the beam energy produces hydrogen concentrations at different depths within the sample. For this set of samples, four beam energies were used $(6.6,6.8,7.0$, and 7.2 MeV), all yielding consistent results indicating a uniform hydrogen content in the films. The numbers reported are averages of the results from these four energies.

\section{Results}

In Fig. 1 we show the germanium content of the films grown for this set of samples as measured by both EPMA and SIMS. These data are plotted according to their corresponding germane fraction in the gasphase, during growth. We also compare these results to our previous HWCVDgrown a-SiGe:H work and typical PECVDgrown a-SiGe:H results.

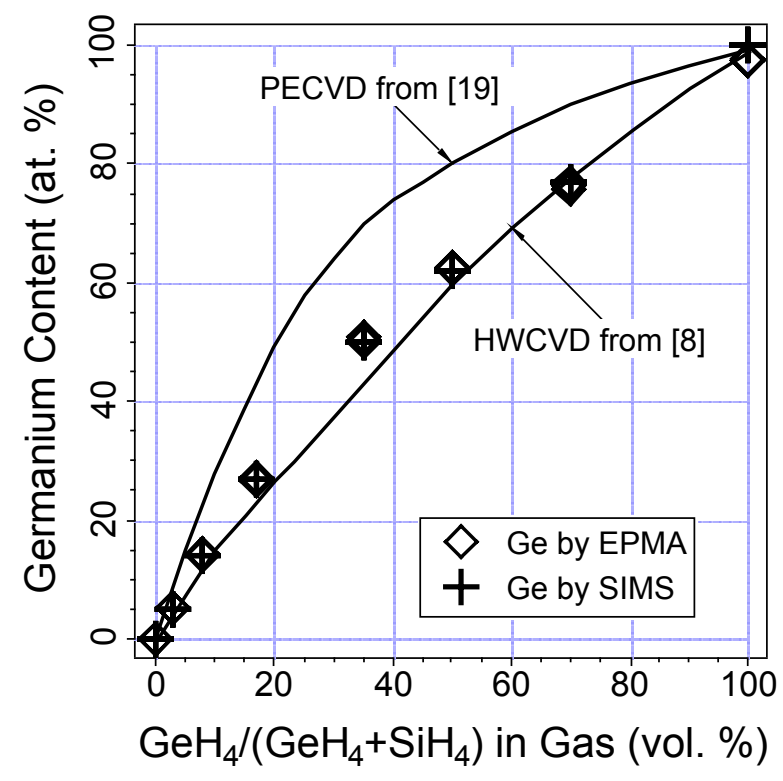

Fig. 1. Germanium incorporation into a-SiGe:H films as a function of the germane fraction in the gas-phase. The lines illustrate the Ge incorporation of a-SiGe:H grown by HWCVD [8] (dashed line) and by PECVD [19] (solid line).
The SIMS data displayed in all three figures have two corrections made to the raw data as described in reference [14]. The first correction utilizes a relative sensitivity factor (RSF) for each element (corrected for isotopic abundance) referenced back to an ion-implanted standard. The corrected concentration is a product of the RSF and the measured ion intensity for the element of interest. This concentration is then divided by the ion intensity for the matrix. Finally, a second correction is done to allow for the alloyed matrix. The SIMS data reported herein are both alloy- and RSF-corrected. All SIMS data are from depth profiles, taking the average between 0.25 and 0.50 $\mu \mathrm{m}$ into the sample. The SIMS C content of all these films ranged between $6 \times 10^{17}$ and $4 \times 10^{18}$ atoms $/ \mathrm{cm}^{3}$.

In Fig. 2, we show the hydrogen contents of these films as measured by NRA, FTIR, and SIMS. These data are plotted according to their corresponding Ge ratio as measured by EPMA. We also include the Tauc's gap [20] for these samples (using the right axis). Hydrogen content measurements are important because of the effects of $\mathrm{H}$ on film properties, e.g., changes to bandgap and the postulated role of $\mathrm{H}$ in Staebler-Wronski instability of electronic properties [21]. 


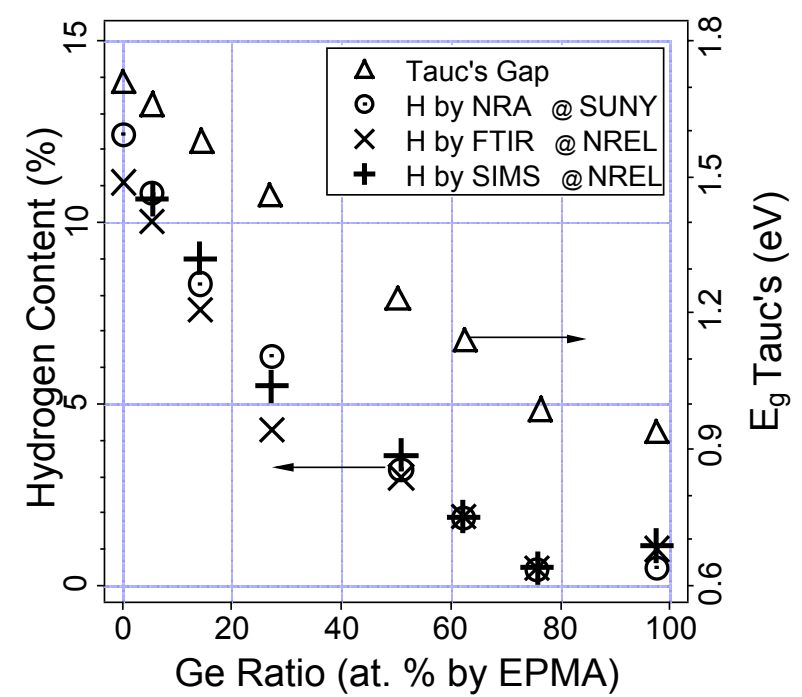

Fig. 2. Hydrogen content (left axis) and Tauc's gaps (right axis) of the a-SiGe:H films as a function of the Ge ratio as measured by EPMA. The far right points are a-Ge: $\mathrm{H}$ grown at $270^{\circ} \mathrm{C}$.

In Fig. 3, we show the oxygen content of these films grown as measured by both EPMA and SIMS. These data are plotted according to their corresponding Ge ratio as measured by EPMA. RBS was not performed on these samples at an appropriate energy to observe the $\mathrm{O}$ cross section $(5.75 \mathrm{MeV})$, and therefore is not used to confirm $\mathrm{O}$ contents.

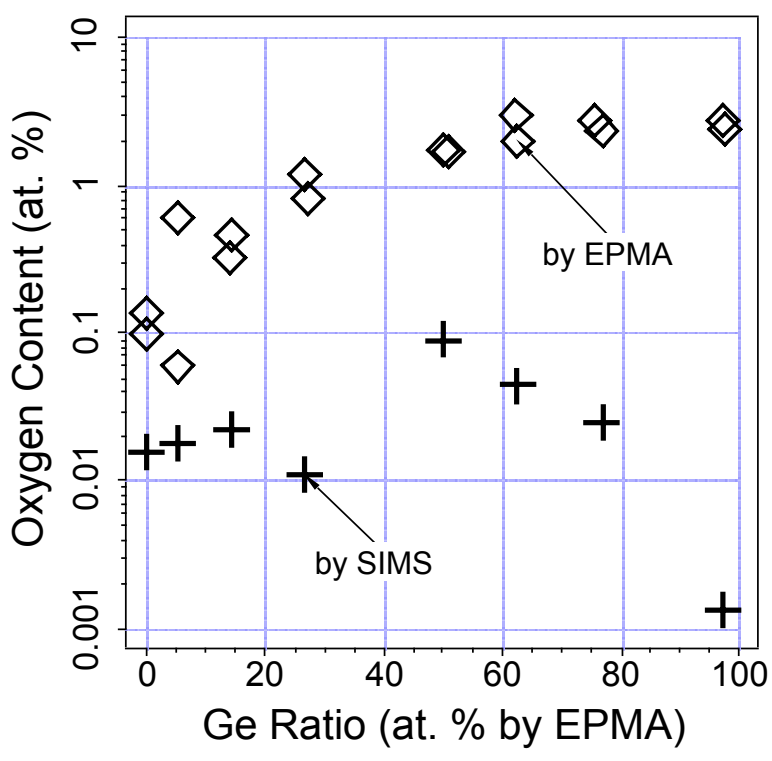

Fig. 3. Oxygen content as measured by both EPMA and SIMS as a function of the Ge ratio as measured by EPMA.

\section{Discussion}

The Ge incorporation (Fig. 1), as well as the electronic properties (e.g., the decrease in photo-todark conductivity ratio with decreasing Tauc's gap) for this set of samples is identical to our previous work [8]. Therefore, we consider these samples to be a representative set with which to compare compositional analysis results.

As we show in Fig. 1, we find agreement to within $\pm 7 \%$ between our SIMS (with the alloy and RSF corrections) and our EPMA measurements for $\mathrm{Ge}$ (and thus $\mathrm{Si}$ ) in these samples. Routine 2-MeV Rutherford backscattering (RBS) measurements were also performed on these samples at SUNY Albany. The EPMA Ge and Si data were validated by comparing actual RBS spectra to spectra generated by a simulation written by Larry Doolittle et al., using the Ge and Si ratios as provided by EPMA.

We use the NRA $\mathrm{H}$ concentrations as the absolute measurement of $\mathrm{H}$ in these films because this measurement does not need referencing back to a standard sample. In Fig. 2, we illustrate how well our FTIR and SIMS measurements of the H content compare to the NRA data. The SIMS data have both the alloy and RSF corrections. All three techniques show the same trend, a decrease in $\mathrm{H}$ with increasing $\mathrm{Ge}$ alloying. The values for $\mathrm{H}$ as measured by each technique show agreement to within $\pm 20 \%$ and are almost identical for some samples. This is true even 
when we use only the wag mode areas of a-Si:H/Si standards to calculate the $\mathrm{H}$ content from the IR absorption spectra of the a-SiGe:H/Si samples, and holds for the sample with more than 70 at.\% Ge. All the IR absorption spectra from these samples (except the a-Ge:H sample) have larger Si-H bands than $\mathrm{Ge}-\mathrm{H}$ bands. The close agreement of the FTIR and SIMS to the NRA indicates that the vast majority of $\mathrm{H}$ in these films is bonded-H. It is well known that in PECVDgrown a-SiGe:H, $\mathrm{H}$ bonds preferentially to $\mathrm{Si}$ by a factor of at least five [22]. This preferential H-bonding to Si seems larger in HWCVD-grown a-SiGe:H.

In Fig. 3, we see the one case in which these analytical techniques do not agree. The $\mathrm{O}$ content as measured by EPMA and SIMS differ by amounts much greater than errors in the data.

Because the EPMA data is averaged from the surface to the sampling depth, the resulting O data are strongly affected by surface oxides and are larger than the SIMS data averaged from 0.25 to $0.50 \mu \mathrm{m}$ into the film. The increase in $\mathrm{O}$ concentration with Ge alloying - over the entire alloy range for the EPMA data and below 50 at.\% Ge for the SIMS data-is consistent with an increase in structural heterogeneity on the nanometer scale of films with increasing Ge alloying $[6,8,10]$. However, it is not clear why the $\mathrm{O}$ concentration as measured by SIMS decreases in films with greater than 50 at.\% Ge.

\section{Conclusions}

We find that alloying a-Si:H with Ge using hot-wire chemical vapor deposition (HWCVD) produces similar results to using to plasma-enhanced chemical vapor deposition (PECVD), namely that alloying lowers the optical gap and photo-response of the alloys. The hydrogen content also decreases with increasing Ge alloying, caused by a strong preferential bonding of $\mathrm{H}$ to Si over Ge.

We find that the compositional measuring techniques that work well for PECVD-grown a-SiGe:H work equally well for HWCVD-grown a-SiGe:H. These techniques include electron probe micro-analysis (EPMA) and secondary ion mass spectrometry (when we take appropriate precautions and calibrate to reference standards). We verified this by comparison to ion beam techniques that are considered "standardless," such as nuclear reaction analysis and Rutherford backscattering. Oxidation of film surfaces produce $\mathrm{O}$ readings by EPMA that are inconsistent with SIMS. Fourier transform infrared spectroscopy is a convenient way to measure the $\mathrm{H}$ content of a-SiGe:H alloys grown by HWCVD.

\section{Acknowledgements}

We gratefully acknowledge helpful discussions with Harv Mahan, Don Williamson, Bolko von Roedern, Alan Gallagher, Dick Crandall, Eugene Iwaniczko, and Howard Branz. This work is supported by the U.S. Department of Energy under Contract No. DE-AC36-98-GO10337.

\section{References}

1. D.E. Carlson and C.R. Wronski, Appl. Phys. Lett. 28, (1976) 671.

2. 2. G. Nakamwa, K. Sato, and Y. Yukimoto, Proc. 16th IEEE Photovoltaic Specialist's Conf. IEEE, 1982, p. 1331. 
3. R.R. Arya, L. Yang, M. Bennett, J. Newton, Y.-M. Li, B. Fieselmann, L. Chen, K. Rajan, G. Wood, C. Poplawski, and A. Wilczynski, Proc. 23rd IEEE Photovoltaic Specialist's Conf., IEEE, 1993, p. 790.

4. S. Guha, J. Yang, A. Banerjee, T. Glatfelter, K. Hoffman, and X. Xu, Technical Digest of the International PVSEC-7, p. 43 (Nagoya, Japan, Nov. 22-26, 1993).

5. S. Wagner, V. Chu, D.S. Shen, J.P. Conde, S. Aljishi, and Z E. Smith, Mat. Res. Soc. Symp. Proc. vol. 118, MRS, Pittsburgh, PA, (1988), p. 623.

6. S. J. Jones, Y. Chen, D. L. Williamson, R. Zedlitz, and G. Bauer, Appl. Phys. Lett. 62, 3267 (1993).

7. A.H. Mahan, J. Carapella, B.P. Nelson, R.S. Crandall, and I. Balberg, Journ. Appl. Phys., 69, 6728 (1991).

8. B.P. Nelson, Y. Xu, D.L. Williamson, B. von Roedern, A. Mason, S. Heck, A.H. Mahan, S.E. Schmitt, A.C. Gallagher, J. Webb, and R. Reedy, Mat. Res. Soc. Symp. Proc. vol. 507, MRS, Warrendale, PA, (1998), p. 447.

9. A.H. Mahan and M. Vanecek, Amer. Inst. of Phys. Conf. Proc. 234, (AIP, New York, 1991), p. 195.

10. D.L. Williamson, Y. Xu, B.P. Nelson, Amer. Inst. of Phys. Conf. Proc. 462, (AIP, New York, 1998), p. 272.

11. B.P. Nelson, R.S. Crandall, E. Iwaniczko, A.H. Mahan, Q. Wang, Y. Xu, and W. Gao, , Mat. Res. Soc. Symp. Proc. in press, MRS, Warrendale, PA, (April, 1999).

12. M.T. Postek, Scanning Electron Microscopy, Ladd Research Industries, chapter four, 1980.

13. R.G. Wilson, F.A. Stevie, and C.W. Magee, Secondary Ion Mass Spectrometry, A Practical Handbook for Depth Profiling and Bulk Impurity Analysis (John Wiley \& Sons, New York, 1989).

14. R.C. Reedy, A.R. Mason, B.P. Nelson, Y. Xu, Amer. Inst. of Phys. Conf. Proc. 462, (AIP, New York, 1998537), p.195.

15. A.A. Langford, M.L. Fleet, B.P. Nelson, W.A. Lanford, and N. Maley, Phys. Rev. B 45, 23, pp. 13367-13377 (1992).

16. G. Lucovsky, Journ. non-Cryst. Sol. 76, (1985) 173. We integrated the wagging bands from 779 to $534 \mathrm{~cm}^{-1}$.

17. W.A. Lanford, H.P. Trautvetter, J.F. Ziegler, and J. Keller, Appl. Phys. Lett., vol. 28, No. 9, p. 566 (1 May 1976)

18. W.A. Lanford, Nuclear Instruments and Methods in Physics Research B66 (1992) 62-85, Elsevier Science Publishers, North-Holland.

19. Y. S. Tsuo, Y. Xu, I. Balberg, and R. S. Crandall, Proc. 22nd IEEE Photovoltaic Specialist's Conf. , IEEE, 1991, p. 1334.

20. J. Tauc, R. Grigorovici, and A. Vancu, Phys. Stat. Sol. 15, 627 (1966).

21. H. M. Branz, Sol. State Com. vol. 105, no. 6, pp. 387-3991 (1998).

22. W. Paul, D.K. Paul, B. von Roedern, J. Blake, and S. Oguz, Phys. Rev. Lett. 46, 1016 (1981). 


\section{REPORT DOCUMENTATION PAGE}

Form Approved OMB NO. 0704-0188

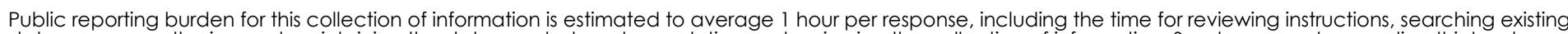

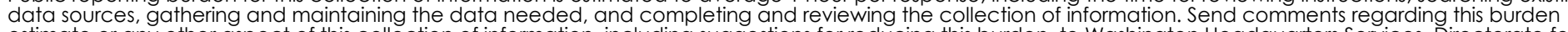

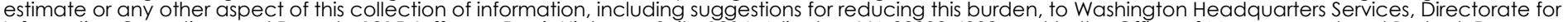

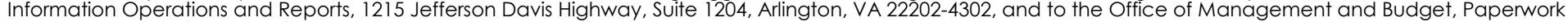
Reduction Project (0704-0188), Washington, DC 20503.

\begin{tabular}{|l|l|l|l|}
\hline 1. AGENCY USE ONLY (Leave blank) & $\begin{array}{l}\text { 2. REPORT DATE } \\
\text { October } 1999\end{array}$ & $\begin{array}{l}\text { 3. REPORT TYPE AND DATES COVERED } \\
\text { Conference paper }\end{array}$ \\
\hline
\end{tabular}

4. TITLE AND SUBTITLE

Techniques for Measuring the Composition of Hydrogenated Amorphous Silicon-Germanium Alloys 6. AUTHOR(S)

B.P. Nelson, Y. Xu, J.D. Webb, A. Mason, R.C. Reedy, L.M. Gedvilas, W.A. Lanford

7. PERFORMING ORGANIZATION NAME(S) AND ADDRESS(ES)

8. PERFORMING ORGANIZATION REPORT NUMBER

9. SPONSORING/MONITORING AGENCY NAME(S) AND ADDRESS(ES)

National Renewable Energy Laboratory

1617 Cole Blvd.

Golden, CO 80401-3393

10. SPONSORING/MONITORING AGENCY REPORT NUMBER

11. SUPPLEMENTARY NOTES

12a. DISTRIBUTION/AVAILABILITY STATEMENT

National Technical Information Service

12b. DISTRIBUTION CODE

U.S. Department of Commerce

5285 Port Royal Road

Springfield, VA 22161

13. ABSTRACT (Maximum 200 words)

We grow hydrogenated amorphous silicon-germanium alloys by the hot-wire chemical vapor deposition technique at deposition rates between 0.5 and 1.4 nanometers per second. We prepared a set of these alloys to determine the concentrations of the alloying elements as measured by various techniques. This set consists of samples throughout the range of germanium alloying from $0 \%(\mathrm{a}-\mathrm{Si}: \mathrm{H})$ to $100 \%$ (a$\mathrm{Ge}: \mathrm{H})$. We find that by making the appropriate calibrations and corrections, our compositional measurements agreement between the various techniques. Nuclear reaction analysis, Fourier transform infrared spectroscopy, and secondary ion mass spectrometry (SIMS) all yield similar hydrogen contents, within $\pm \hat{E} 20 \%$ for each sample. Electron probe micro-analysis (EPMA) and SIMS yield silicon and germanium contents within $\pm \hat{E} 7 \%$ of each other with results being confirmed by Rutherford backscattering. EPMA oxygen measurements are affected by highly oxidized surface layers, thus these data show larger O concentrations than those measured by SIMS.

14. SUBJECT TERMS

15. NUMBER OF PAGES

6. PRICE CODE

17. SECURITY CLASSIFICATION

OF REPORT

Unclassified
18. SECURITY CLASSIFICATION OF THIS PAGE Unclassified
19. SECURITY CLASSIFICATION OF ABSTRACT

Unclassified
20. LIMITATION OF ABSTRACT

UL 